\title{
Interaction of Basal Foliage Removal and Late-Season Fungicide Applications in Management of Hop Powdery Mildew
}

David H. Gent, United States Department of Agriculture-Agricultural Research Service (USDA-ARS), Forage Seed and Cereal Research Unit, and Department of Botany and Plant Pathology, Oregon State University, Corvallis 97331; Claudia Probst, Mark E. Nelson, and Gary G. Grove, Department of Plant Pathology, Washington State University Irrigated Agriculture Research and Extension Center, Prosser 99350; Stephen T. Massie, Pharsalia Hop Company, Zionville, NC 28698; and Megan C. Twomey, Department of Botany and Plant Pathology, Oregon State University, Corvallis

\begin{abstract}
Gent, D. H., Probst, C., Nelson, M. E., Grove, G. G., Massie, S. T., and Twomey, M. C. 2016. Interaction of basal foliage removal and late-season fungicide applications in management of hop powdery mildew. Plant Dis. 100:1153-1160.

Canopy management is an important aspect of control of powdery mildew diseases and may influence the intensity of fungicide applications required to suppress disease. In hop, powdery mildew (caused by Podosphaera macularis) is most damaging to cones when infection occurs during bloom and the juvenile stages of cone development. Experiments were conducted over 3 years to evaluate whether fungicide applications could be ceased after the most susceptible stages of cone development (late July) without unduly affecting crop yield and quality when disease pressure was moderated with varying levels of basal foliage removal. In experimental plots of 'Galena' hop, the incidence of leaves with powdery mildew was similar whether fungicides were ceased in late July or made in late August. Disease levels on leaves were unaffected by the intensity of basal foliage removal, whereas the intensity of basal foliage removal interacted with the duration of fungicide applications to affect disease levels on cones. Similar experiments conducted in large plots of 'Tomahawk' hop in a commercial hop yard similarly found no significant impact on disease levels on leaves from either the duration of fungicide

applications or intensity of basal foliage removal. In contrast, on cones, application of fungicides into August had a modest, suppressive effect on powdery mildew. There was also some evidence that the level of powdery mildew on cones associated with fungicide treatment was influenced by the intensity of basal foliage removal. When fungicide applications ceased in late July, there was a progressive decrease in the incidence of cones with powdery mildew with increasing intensity of basal foliage removal. Removing basal foliage two to three times allowed fungicide applications to be terminated in late July rather than late August without diminishing disease control on cones, yield, or cone quality factors. Thus, this study further establishes that fungicide applications made during the early stages of hop cone development have the strongest effect on suppression of powdery mildew on cones. The additive effect of fungicide applications targeted to the periods of greatest cone susceptibility and canopy management to reduce disease favorability may obviate the need for fungicide applications later in the season. This appears to be a viable strategy in mature hop yards of certain cultivars when disease pressure is not excessively high.
\end{abstract}

Plant canopy management is an important aspect of controlling powdery mildew diseases. Biotrophic powdery mildew fungi are generally highly attuned to conditions favoring development of their host such as leaf growth (Jarvis et al. 2002; Merry et al. 2013), and the amount of susceptible host tissue present often is correlated with airborne inoculum density and overall disease risk (Royle 1978). Factors such as planting density, fertilization rate, irrigation, and leaf removal may influence the infection rate and severity of powdery mildew outbreaks on various hosts (Austin and Wilcox 2011; Austin et al. 2011; Chellemi and Marois 1992; Jarvis et al. 2002). Canopy management also may alter plant microclimate (English et al. 1989; Thomas et al. 1988), light penetration, and coverage of fungicides (Austin et al. 2011). In some pathosystems, modification of plant canopy may permit reductions in fungicide applications (Hed et al. 2015). Given the potential relationship between canopy density and powdery mildew development, there is

Corresponding author: David H. Gent, E-mail: Dave.Gent@ars.usda.gov

Mention of a trademark, proprietary product, or vendor does not constitute a guarantee or warranty of the product by the USDA and does not imply its approval to the exclusion of the products or vendors that may also be suitable.

*The $\boldsymbol{e}$-Xtra logo stands for "electronic extra" and indicates that two supplementary tables are published online.

Accepted for publication 23 January 2016.

http://dx.doi.org/10.1094/PDIS-10-15-1232-RE

This article is in the public domain and not copyrightable. It may be freely reprinted with customary crediting of the source. The American Phytopathological Society, 2016. motivation to understand how cultural practices that reduce foliage influence disease development and interact with other management tactics.

In the case of powdery mildew of hop, caused by Podosphaera macularis, cultural practices that eliminate susceptible host tissue and decrease canopy density similarly can aid in disease management (Gent et al. 2012; Turechek et al. 2001). The climbing shoots of hop plants (termed bines) are formed annually from buds on the perennial root system, reaching heights of $6 \mathrm{~m}$ or more by the summer solstice. Midseason removal of basal foliage has long been practiced in hop to reduce canopy density, alter the microclimate around the plant, and eliminate inoculum of the downy mildew pathogen Pseudoperonospora humuli (Romanko 1964; Royle and Kremheller 1981) and Podosphaera macularis (Gent et al. 2008; Royle 1978). Historically, basal foliage removal was conducted by hand or using specialized equipment (Neve 1991), although this practice is now mostly accomplished with contact herbicides (Gent et al. 2008; Romanko 1964) or solutions of nitrogen fertilizers. An important consideration is how intensive basal foliage removal may affect yield in both the current and successive seasons (Neve 1991; Williams 1962). This impact may depend on age of a hop yard and cultivar (Williams 1962). It is unclear how sensitive hop cone yield is to basal foliage removal in modern, highyielding hop cultivars that are susceptible to powdery mildew.

Basal foliage removal can reduce levels of powdery mildew, although additional management tactics are needed to suppress the disease to acceptable levels. Fungicides are an essential component of disease management in susceptible hop cultivars (Gent et al. 2008; Mahaffee et al. 2009; Nelson et al. 2015). A typical fungicide program for powdery mildew in the Pacific Northwestern United States may involve six or more applications per season on highly susceptible cultivars (Gent et al. 2012; Sherman and Gent 2014). Of 
particular importance is control of the disease during bloom and juvenile stages of cone development, the so-called stages I to III of cone development (Kavalier et al. 2011), which is when cones are maximally susceptible to powdery mildew (Nelson et al. 2015; Twomey et al. 2015). The fungicide quinoxyfen is especially efficacious when applied during these stages of cone development. A recent metaanalysis of individual participant data by Nelson et al. (2015) found that one or two applications of the fungicide quinoxyfen during the early stages of cone development reduced the incidence of cones with powdery mildew at harvest by as much as $65 \%$ compared with all other fungicides and fungicide programs. In related studies, yield of $\alpha$-acids (the primary bittering acids of economic importance in hop) were increased $20 \%$ when quinoxyfen applications were made through late July as compared with mid-July due to improved control of the disease (Gent et al. 2014). However, fungicide applications made after stage II of cone development (i.e., August and September) had, on average, only modest effects on yield or cone quality factors. Some year-dependent yield and cone quality effects were detected, suggesting that disease pressure may influence the value of lateseason fungicide applications (Gent et al. 2014).

Collectively, these studies may indicate that late-season management of powdery mildew might be possible with fewer fungicide applications if treatments were appropriately targeted to the most strongly affected stages of cone development and disease pressure was sufficiently low. To test this idea, the research presented herein was conducted to satisfy two objectives. The first was to test whether fungicide applications for powdery mildew could be ceased after the most susceptible stages of cone development in late July and early August without negatively affecting crop yield and quality. The second was to determine how termination of fungicide applications at this stage of cone development may interact with the intensity of basal foliage removal.

\section{Materials and Methods}

Field sites and experimental design. Field experiments were conducted during 2012 to 2014 in an experimental hop yard located at the Washington State University Irrigated Agriculture Research and Extension Center near Prosser, WA, planted to 'Galena' hop in 2006. Related experiments also were conducted in a commercial hop yard near Toppenish, WA, planted to 'Zeus' hop in 2008. The general approach at both locations was to create varying levels of disease intensity by overlaying three levels of basal foliage removal intensity onto fungicide programs that terminated at different times late in the season.

Experimental plot studies. In the experimental plots at Prosser during each year, three fungicide treatments were evaluated that consisted of (i) no fungicides; (ii) fungicide applications every 10 to 15 days using a rotation of two applications of quinoxyfen at 94.9 to $126.5 \mathrm{~g} / \mathrm{ha}$ (Quintec; Dow AgroSciences, Indianapolis, IN) alternated with two applications of myclobutanil at $280.2 \mathrm{~g} / \mathrm{ha}$ (Rally 40WSP; Dow AgroScienes), with applications ceasing in late July (30 or $31 \mathrm{July}$ ); and (iii) the same fungicide applications as above but with one (2013 and 2014) or two (2012) additional applications of myclobutanil during August. In all experiments, applications began in late May (24 to 28 May) and, in total, six fungicide applications were made in plots where treatments ceased in late July and seven to eight applications in plots that were treated into August. Quinoxyfen was applied in the first two applications and also in the fifth and sixth applications (made in July), coincident with stages I and II of cone development, the period of greatest cone susceptibility to powdery mildew (Twomey et al. 2015) and efficacy from this fungicide (Nelson et al. 2015). Fungicides were applied with a backpack mist blower (STIHL model number SR420; STIHL, Virginia Beach, VA) in an application volume of water at 327 to 1,300 liters/ha, depending on plant size.

Overlaid on each of these fungicide treatments were three levels of basal foliage removal intensity: none, one application of the herbicide paraquat (Gramoxone Inteon; Syngenta Crop Protection, Greensboro, NC), or two applications of paraquat. The rate applied was paraquat at $560.4 \mathrm{~g} / \mathrm{ha}$ plus $1 \%$ ( $\mathrm{vol} / \mathrm{vol})$ crop oil concentrate as a surfactant. The first paraquat application was made on 9 to 20 July, year dependent, and the second application was made 10 to 12 days later. Applications were made with a backpack sprayer in an application volume equivalent to 468 liters/ha. In each year of the experiment, the same fungicide and basal foliage removal treatments were applied to the same plots to detect multiyear effects on yield and disease levels.

A plot consisted of nine plants in a single row arranged in a spacing of 1 by $3 \mathrm{~m}$ under a 3-m-tall trellis, with one vertical string provided per plant. There was a two-way factorial structure of the three levels of fungicide and three levels of basal foliage removal, with each combination of fungicide and basal foliage removal replicated four times in a randomized complete block design. Only the middle seven plants in each plot were evaluated for disease or yield to minimize edge effects between plots. Disease assessments were made using standard procedures, as described previously (Gent et al. 2014). In brief, the incidence of leaves with powdery mildew was assessed by arbitrarily selecting four leaves from both the east and west side of each plant and examining each leaf for signs of powdery mildew. In 2012, foliar disease evaluations began 19 June and were repeated approximately biweekly until 1 August. In 2014, three biweekly assessments were conducted beginning 10 July. Data from 2013 are not presented due to phytotoxicity associated with the paraquat applications. Individual disease ratings were utilized to calculate area under the disease progress curve, standardized for the duration of disease evaluation (AUDPCS) (Madden et al. 2007).

During harvest in the first week of September, one lateral branch was selected arbitrarily from the top 2 to $3 \mathrm{~m}$ of each of the seven middle plants per plot. The total number of cones and number of cones with powdery mildew (based on a visual inspection) were counted and recorded to determine percent disease incidence.

The plots were harvested using a hop-picking machine to estimate cone yield on a per-plant basis. The fresh weight of the cones for each plot was recorded, and a subsample of harvested cones (approximately $70 \mathrm{~g}$ ) was collected and dried for 48 to $72 \mathrm{~h}$ at $60^{\circ} \mathrm{C}$ in order to determine percent dry matter content of the cones. This value was then used to standardize yield to dry weight per plant.

A second subset of harvested cones was collected and dried overnight to approximately 8 to $10 \%$ moisture. From these cones, bittering acids content was determined by standard spectrophotometric methods (ASBC 2009). A subsample of the dried cones was rated for color using a 1-to-10 rating scale commonly used in the U.S. hop industry, as described by Twomey et al. (2015). Color ratings were conducted so that the rater was unaware of the treatment each sample received. The same person performed the ratings in all years.

Commercial hop yard studies. Six treatments also were evaluated in a commercial yard planted to Zeus during 2012 to 2014, consisting of three levels of basal foliage removal and two dates of the last fungicide application. The fungicide treatments evaluated were: (i) fungicide applications made up to late July to early August (29 July to 1 August) and (ii) applications made until late August (28 August). Until late July, the yard was managed using standard production practices of the cooperating grower, including weekly to biweekly applications of sulfur fungicides applied to the entire hop yard up to the first week of July, and thereafter two sequential applications of quinoxyfen (Quintec at $126.5 \mathrm{~g} / \mathrm{ha}$ ) applied in mid-July and late July to early August, as noted previously.

In plots that received fungicide after late July or early August, two additional applications were made at 14-day intervals consisting of a mixture of pyraclostrobin and boscalid (Pristine Fungicide; BASF, Research Triangle Park, NC) applied at the rate of $980.7 \mathrm{~g} / \mathrm{ha}$ in 2012 and 1,961 g/ha in 2013 and 2014. Thus, in 2012, each application contained pyraclostrobin at $125.5 \mathrm{~g} / \mathrm{ha}$ and boscalid at $247.1 \mathrm{~g} / \mathrm{ha}$, which was the lower range of the recommended rate on the manufacturer's U.S. label. Application rates were twice this level in 2013 and 2014, which corresponded to the maximum rate specified on the manufacturer's label. Fungicides were applied using the cooperating grower's air-blast orchard sprayer (LectroBlast; Progressive Ag., Inc, Modesto, CA) in an application volume of 375 liters/ha, which was the standard practice of the grower. 
Overlaid on the fungicide treatments was basal foliage removal with one, two, or three applications of a herbicide desiccant (carfentrazone at $35.9 \mathrm{~g} / \mathrm{ha}$; Aim EC; FMC Corp., Philadelphia) amended with $1 \%(\mathrm{vol} / \mathrm{vol}) \mathrm{crop}$ oil. Carfentrazone was used in the commercial yard experiment instead of paraquat due to concerns by the cooperating grower of exceeding allowable maximum residue levels of paraquat in certain export markets. The first herbicide application was made on 15 July and subsequent applications, where made, were conducted at 2-week intervals. The grower made the first herbicide application to the entire field using their standard farm equipment The second and third applications were made to specific plots with a backpack sprayer in an application volume equivalent to 187 liters/ha. In all applications, the spray solution was directed at the leaves on the lower $1 \mathrm{~m}$ of the bines.

Similarly to the experiments at Prosser, there was a factorial structure of the treatments with factors of (i) duration of fungicide applications and (ii) intensity of basal foliage removal. Plots were arranged as a randomized complete block design with five replications per

Table 1. Mixed-model repeated-measures analysis of the effect of basal foliage removal (B), duration of fungicide applications (F), and year (Y) on the incidence of hop leaves and cones with powdery mildew, yield, and cone quality factors in experiments with Galena hop ${ }^{\text {a }}$

\begin{tabular}{|c|c|c|c|c|c|c|c|c|c|c|c|c|c|c|c|c|}
\hline \multirow[b]{2}{*}{ Effect } & \multicolumn{4}{|c|}{ Leaves with powdery mildew } & \multicolumn{4}{|c|}{ Cones with powdery mildew ${ }^{b}$} & \multicolumn{4}{|c|}{ Yield of $\alpha$-acids ${ }^{b}$} & \multicolumn{4}{|c|}{ Cone color ${ }^{c}$} \\
\hline & N-DF & D-DF & $\boldsymbol{F}$ & $P$ & N-DF & D-DF & $\boldsymbol{F}$ & $P$ & N-DF & D-DF & $\boldsymbol{F}$ & $\boldsymbol{P}$ & N-DF & D-DF & $\boldsymbol{F}$ & $\boldsymbol{P}$ \\
\hline $\mathrm{F}$ & 2 & 51 & 32.55 & $<0.001$ & 2 & 51 & 51.36 & $<0.001$ & 2 & 24.13 & 0.12 & 0.883 & 1.84 & 33.5 & 34.35 & $<0.001$ \\
\hline $\mathrm{B}$ & 2 & 51 & 1.13 & 0.332 & 2 & 51 & 1.01 & 0.370 & 2 & 24.13 & 0.02 & 0.976 & 2 & 33.5 & 1.66 & 0.205 \\
\hline $\mathrm{F} \times \mathrm{B}$ & 4 & 51 & 0.38 & 0.820 & 4 & 51 & 3.04 & 0.025 & 4 & 24.11 & 0.46 & 0.762 & 3.61 & 33.5 & 2.18 & 0.098 \\
\hline Y & 1 & 51 & 176.93 & $<0.001$ & 1 & 51 & 191.41 & $<0.001$ & 1 & 27.01 & 4.33 & 0.047 & 1 & 33.5 & 0.72 & 0.402 \\
\hline $\mathrm{F} \times \mathrm{Y}$ & 2 & 51 & 16.35 & $<0.001$ & 2 & 51 & 20.1 & $<0.001$ & 2 & 27 & 0.06 & 0.938 & 1.84 & 33.5 & 5.78 & 0.008 \\
\hline $\mathrm{B} \times \mathrm{Y}$ & 2 & 51 & 2.07 & 0.137 & 2 & 51 & 1.12 & 0.336 & 2 & 27 & 3.05 & 0.064 & 2 & 33.5 & 0.33 & 0.721 \\
\hline $\mathrm{F} \times \mathrm{B} \times \mathrm{Y}$ & 4 & 51 & 0.27 & 0.894 & 4 & 51 & 1.09 & 0.371 & 4 & 26.98 & 1.53 & 0.221 & 3.61 & 33.5 & 0.61 & 0.643 \\
\hline
\end{tabular}

a $\mathrm{N}-\mathrm{DF}$ and $\mathrm{D}-\mathrm{DF}=$ numerator and denominator degrees of freedom, respectively.

b Leaves with powdery mildew was expressed as relative area under the disease progress curve. Measurements were repeated over year. Covariance structures for the factor year were selected based on the Akaike Information Criterion. A compound symmetry covariance structure was used for analysis for yield; a heterogeneous compound symmetry structure was specified for the covariance in the other analyses.

c Analysis of cone color was conducted using ranks of cone color rating and an analysis of variance-type statistic, as described by Shah and Madden (2004).

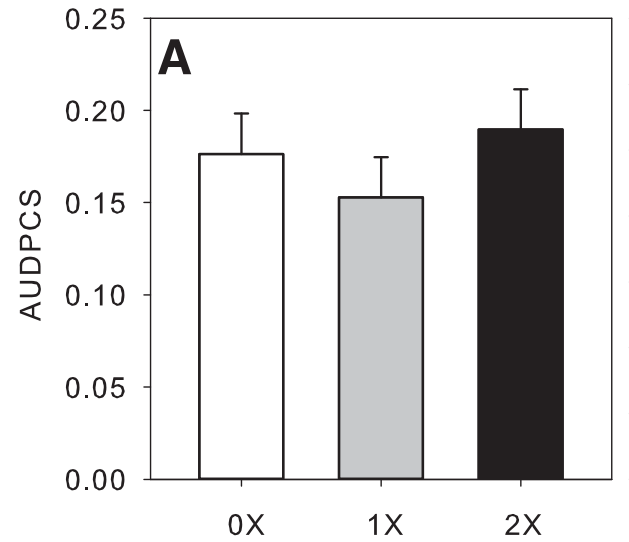

Times basal foliage removed

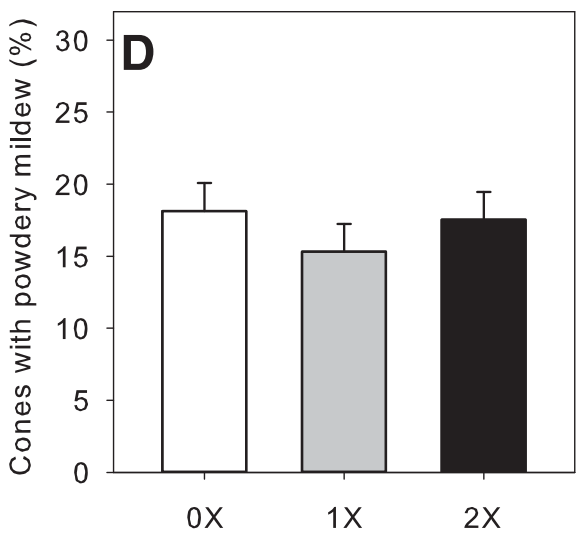

Times basal foliage removed

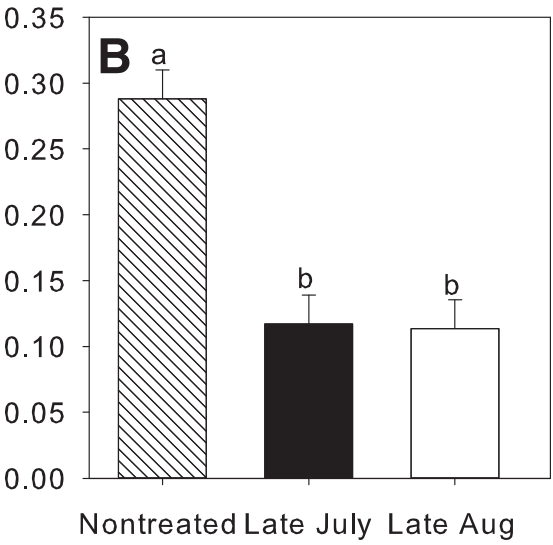

Last fungicide application

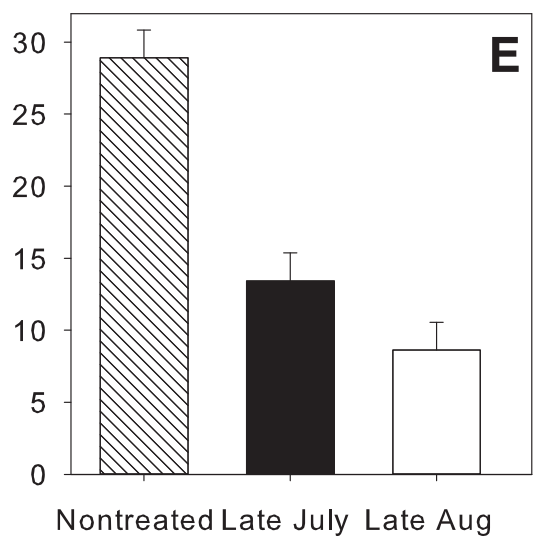

Last fungicide application

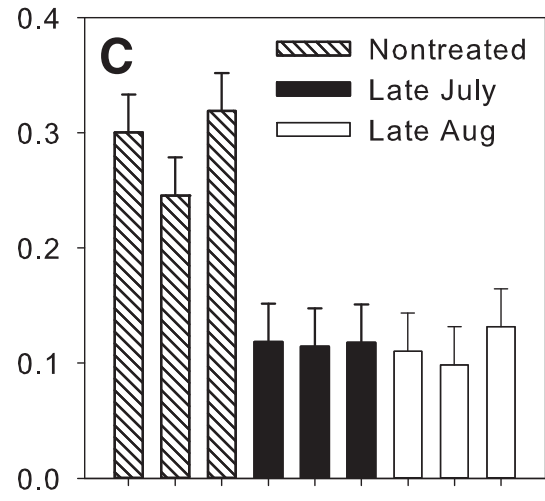

$0 \times 1 \times 2 \times$ ox $1 \times 2 \times$ ox $1 \times 2 \times$

Times basal foliage removed

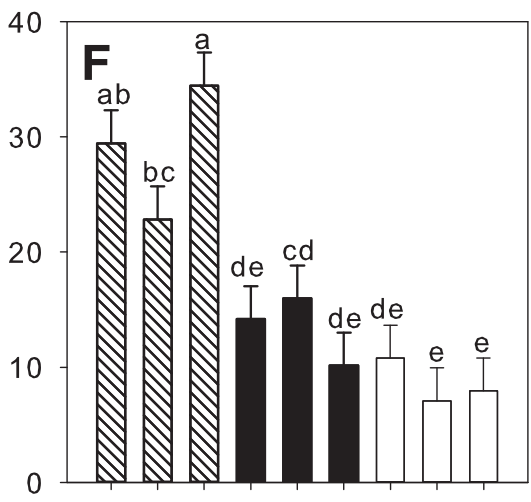

$0 \times 1 \times 2 \times$ ox $1 \times 2 \times$ ox $1 \times 2 \times$

Times basal foliage removed

Fig. 1. Incidence of powdery mildew on $\mathbf{A}$ to $\mathbf{C}$, hop leaves and $\mathbf{D}$ to $\mathbf{F}$, cones in relationship to intensity of basal foliage removal with a desiccant herbicide and duration of fungicide applications in Galena hop. The same treatments were applied to the same plots in each year from 2012 to 2014 , and analyzed as a repeated-measures design in a mixed-effect model. Data presented here are from 2012 and 2014; 2013 data were excluded due to crop damage from the basal foliage removal treatments. Experiments were conducted in plots near Prosser, WA. AUDPCS = time-standardized area under the disease progress curve. Letters indicate significant treatment effects based on the mixed-model analysis $(P=$ 0.05); absence of letters indicates that a factor was nonsignificant or the interaction term was significant (as in F). Error bars indicate standard errors. 
fungicide-basal foliage removal combination. Each plot consisted of three rows, each containing 13 plants. Plots were separated by at least one row that was not treated with fungicides and herbicides after late July or early August.

Disease assessments and yield measurements were conducted as described by Gent et al. (2014). In brief, four to six disease assessments for powdery mildew on leaves were conducted each year, beginning in mid- to late June and continuing every 2 weeks until early to mid-August. Powdery mildew incidence on leaves was assessed by inspecting 10 leaves on each of 10 plants per plot (100 leaves/plot) every 2 weeks. At harvest, the incidence of cones with powdery mildew was determined by collecting cones from lateral branches at heights of approximately 3,4 , and $5 \mathrm{~m}$ from the ground on 10 plants from each plot. The cones were bulked before selecting 15 cones arbitrarily from each plant, for a total of 150 cones/plot. Each cone was evaluated for signs of powdery mildew with the aid of a stereomicroscope, when necessary. Harvest dates ranged from 10 to 17 September among years. Yield measurements, cone chemical analysis, and cone quality evaluations were conducted similarly to the experiments at Prosser, with the exception that 10 plants were harvested per plot to estimate yield.

Data analysis. The data from both experiments were analyzed using mixed-effects models. For a given location-year, data were analyzed considering the factors of fungicide treatment, basal foliage removal intensity, and their interaction as fixed effects. Block was a random effect. Analyses were conducted using the GLIMMIX procedure in SAS (version 9.4; SAS Institute, Cary, NC), with the distribution of the response variables specified as normal and with the default link function in GLIMMIX. If a significant treatment effect was found, least-squares means for the factors or their interaction were compared for individual treatments using the lines options in GLIMMIX without adjustment for multiple comparisons. Results of these analyses are provided for completeness as supplementary materials (Supplementary Tables S1 and S2).

Because the same treatments were applied to the same plots in each year of the experiment, data were collected from the same experimental units over multiple years and, therefore, the experiments involved repeated measures. Consequently, data from 2012 to 2014 also were analyzed as a repeated-measures design using the GLIMMIX procedure. Multiple covariance structures for the residuals were investigated, and the simplest covariance structure consistent with the data was selected based on the Akaike Information Criterion. Degrees of freedom were estimated by the Kenward-Roger method. Disease incidence data for cones were transformed using an arscin transformation to stabilize variances.

The ordinal rating scale used for cone color was analyzed using an analysis of variance-type statistic in the MIXED procedure in SAS (version 9.4) and macros developed by Brunner et al. (2002), as per the methods described by Shah and Madden (2004). Again, this analysis was conducted for each location-year individually and also as a repeated-measures analysis over years. Estimated

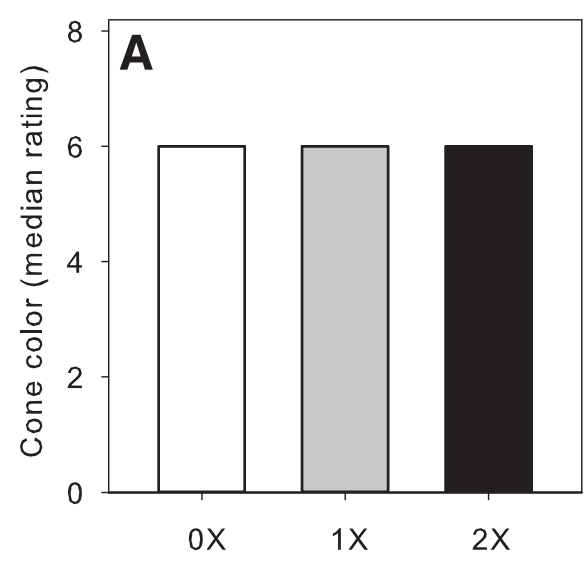

Times basal foliage removed

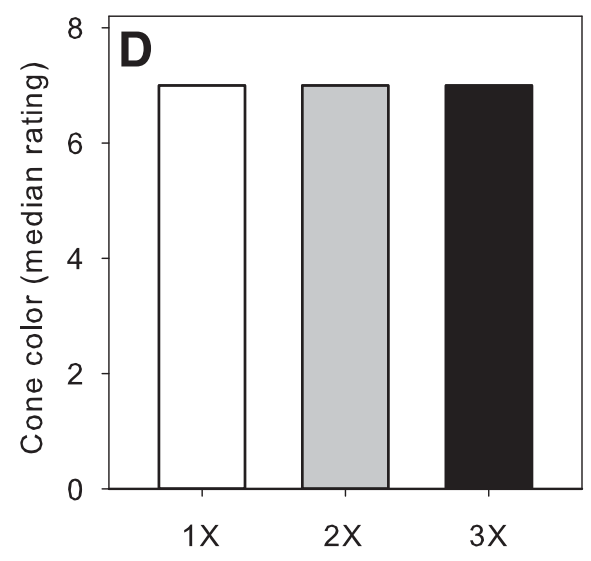

Times basal foliage removed

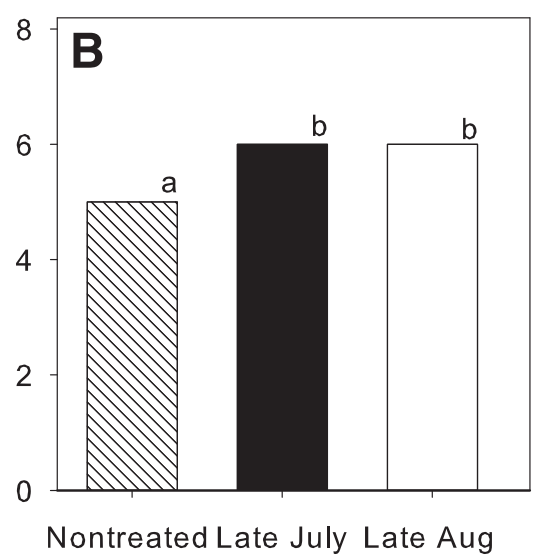

Last fungicide application

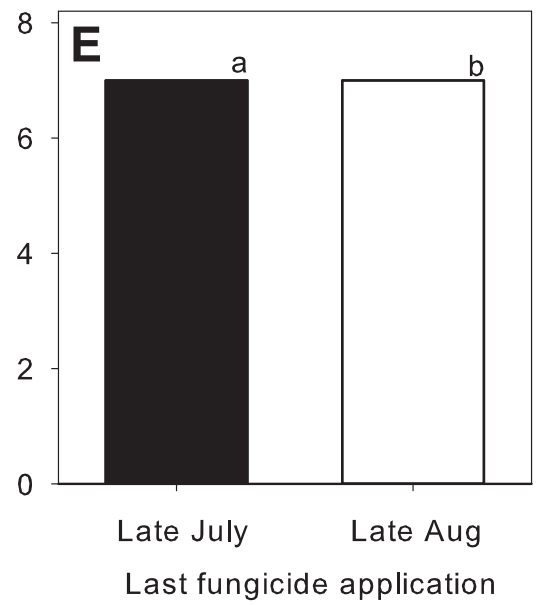

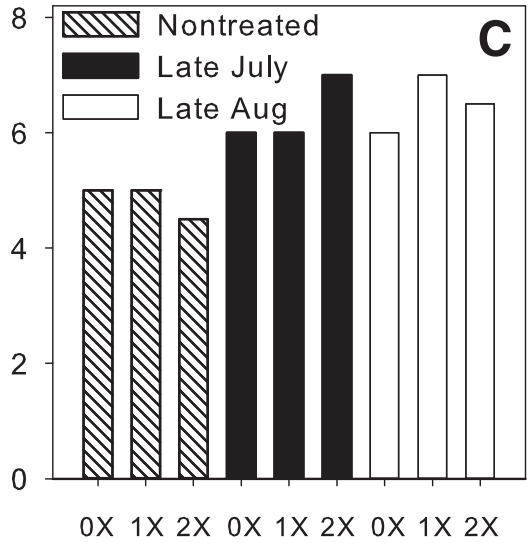

Times basal foliage removed

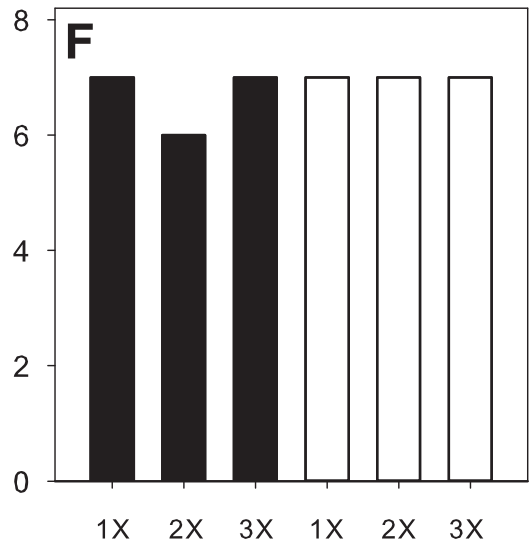

Times basal foliage removed

Fig. 2. Hop cone color as influenced by intensity of basal foliage removal with a desiccant herbicide and duration of fungicide applications for powdery mildew control. Median values of cone color are presented. Cone color was assessed using a 1-to-10 ordinal scale, where 10 represents the best possible color and color degrades progressively with smaller values (Twomey et al. 2015). Data are for A to C, Galena hop and D to F, Zeus hop. The same treatments were applied to the same plots in each year from 2012 to 2014 , and analyzed as a repeated-measures design appropriate for ordinal data in a mixed-effect model (Brunner et al. 2002; Shah and Madden 2004). Letters indicate a significant treatment effect $(P=0.05)$; absence of letters indicates that a factor was nonsignificant. Data presented for Galena is from 2012 and 2014 only; 2013 data are excluded due to crop damage from the basal foliage removal treatments. Note that, in $\mathrm{E}$, the medians are identical but treatment effects were significant in the nonparametric analysis of the ranks, with relative effects of $0.57(95 \%$ confidence internal $[\mathrm{Cl}] 0.52$ to 0.61$)$ for fungicide applications ending in August versus $0.43(\mathrm{Cl} 0.39$ to 0.48$)$ for fungicide applications ending in July. Experiments in Galena were conducted in experimental plots near Prosser, WA and experiments with Zeus were conducted in a commercial hop yard near Toppenish, WA. 
relative treatment effects and their confidence intervals were calculated using the macros "LD_CI" and "F2_LD_FI".

\section{Results}

Experimental plot studies. The incidence of leaves with powdery mildew was similar among the basal foliage removal treatments (basal foliage removal effect $P=0.332$; Table 1; Fig. 1A) but significantly reduced by fungicide application compared with the nontreated control $(P<0.001$; Table 1; Fig. 1B). The magnitude of disease on leaves varied between years (year effect, $P<0.001$ ), as did the reduction in powdery mildew from fungicide treatment (fungicide-year interaction, $P<$ 0.001). However, in both 2012 and 2014, there was no difference in disease levels on leaves between plots treated with fungicides up to July compared with August (Fig. 1B). This effect was similar among basal foliage removal treatments $(P=0.820$; Fig. $1 \mathrm{C})$.

Generally similar trends were observed on cones (Table 1; Fig. 1D to $F$ ) although, unlike on leaves, there was an interaction of basal foliage removal and duration of fungicide applications (fungicidebasal foliage removal interaction, $P=0.025$ ). Disease incidence was greatest on cones not treated with fungicides, mostly independent of intensity of basal foliage removal. Powdery mildew levels on cones were reduced in plots that received fungicide applications until August and had basal foliage removed once or twice as compared with ceasing fungicide applications in July and removing basal foliage only once (Fig. 1F).
Cone color was improved modestly in both years by fungicide treatments (fungicide effect, $P<0.001$ ), with the magnitude of color improvement year-dependent (fungicide-year interaction, $P=$ 0.008). Compared with nontreated plots, the median cone color in plots treated with fungicides was increased from median rating of 5.5 to 6 in 2012 and 4 to 6.5 in $2014(P<0.001$; Table 1; Fig. 2B). Differences in cone color were not significant between plots that received fungicides until July versus August in either year, as indicated by the overlapping confidence intervals of the estimated relative treatment effects (Fig. 2C). Yield of $\alpha$-acids was unaffected by the treatments $(P \geq 0.064$ for all factors and interactions; Table 1; Fig. 3A to C).

Commercial hop yard studies. There was a numerical tendency for incidence of leaves with powdery mildew to decrease as the intensity of basal foliage removal increased and with fungicide applications into August (Fig. 4A to C) but these impacts were not significant in a repeated-measures analysis (basal foliage removal effect, $P=0.333$; fungicide effect, $P=0.275$; Table 2). On cones, however, application of fungicides into August had a modest impact, reducing the incidence of cones with powdery mildew from 87 to $81 \%(P=0.001)$. There was some evidence that the level of powdery mildew on cones associated with fungicide treatment was influenced by the intensity of basal foliage removal (fungicide-basal foliage removal interaction, $P=0.076$; Table 2; Fig. 4D to $F$ ). When fungicide applications were made through August, there was no impact of basal

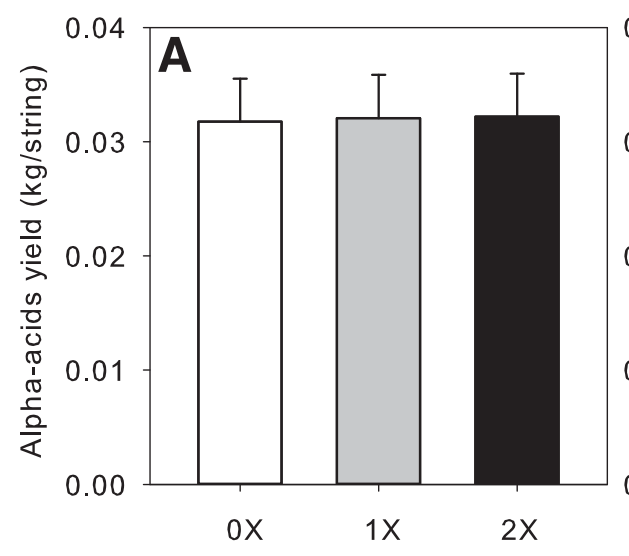

Times basal foliage removed

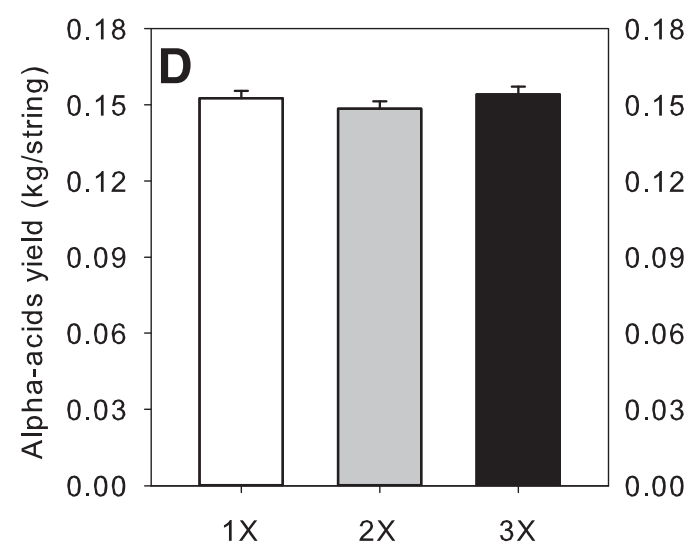

Times basal foliage removed

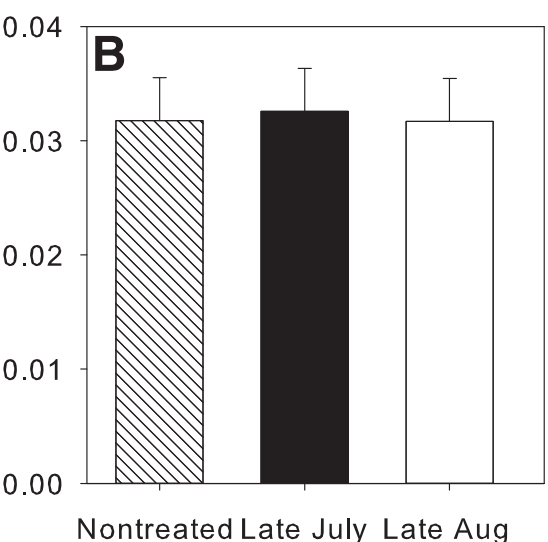

Last fungicide application

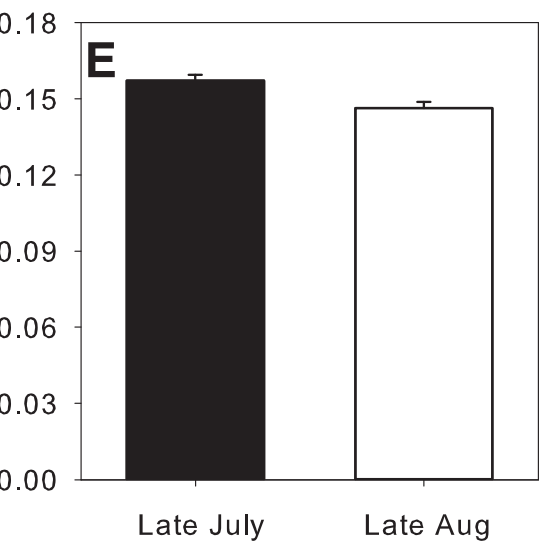

Last fungicide application

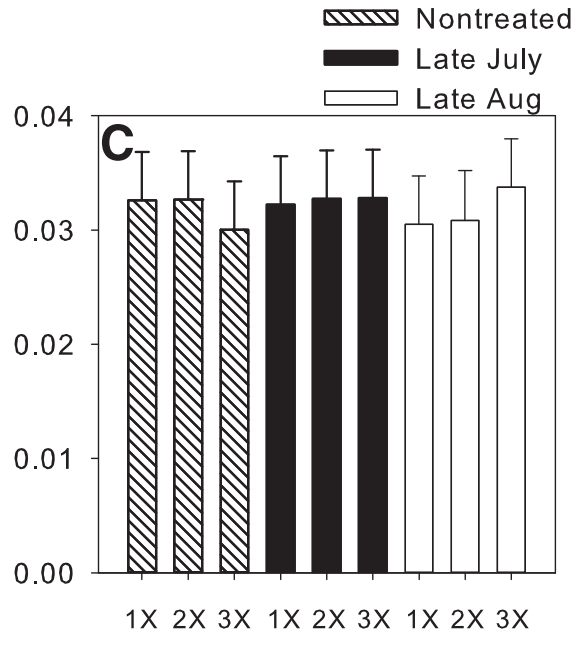

Times basal foliage removed

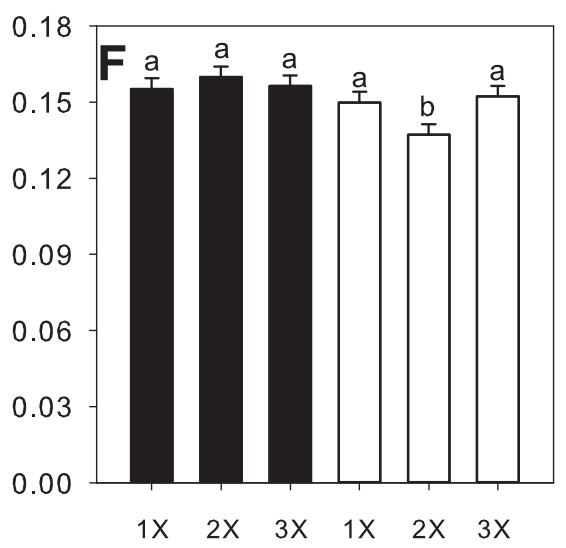

Times basal foliage removed

Fig. 3. Yield of $\alpha$-acids in $\mathbf{A}$ to $\mathbf{C}$, Galena and $\mathbf{D}$ to $\mathbf{F}$, Zeus hop in relation to intensity of basal foliage removal with a desiccant herbicide and duration of fungicide applications for powdery mildew. The same treatments were applied to the same plots in each year from 2012 to 2014, and analyzed as a repeated-measures design. Data presented for Galena are from 2012 and 2014 only; 2013 data were excluded due to crop damage from the basal foliage removal treatments. Experiments in Galena were conducted in plots near Prosser, WA and experiments with Zeus were conducted in a commercial hop yard near Toppenish, WA. Letters indicate significant treatment effects based on the mixedmodel analysis $(P=0.05)$; absence of letters indicates that a factor was nonsignificant or the interaction term was significant (as in $\mathrm{F})$. Error bars indicate standard errors. 
foliage removal intensity on the level of powdery mildew on cones. However, when fungicide applications ceased earlier, there was a progressive decrease in the incidence of cones with powdery mildew with increasing intensity of basal foliage removal (Fig. 4F). When fungicide applications were terminated in late August, basal foliage removal two or three times gave disease control on cones equivalent to that achieved with two additional fungicide applications (independent of basal foliage removal intensity).

Improvements in cone color associated with duration of fungicide application were modest (Fig. 2E, note identical median) but significant and year dependent based on the nonparametric rank-based analysis (fungicide-year interaction, $P=0.024$; Table 2). In 2012 and 2013, median cone color rating was 7 in plots that received either fungicide treatment and not significantly different from each other $(P \geq 0.184)$. In contrast, in 2014, median cone color rating improved from 6 to 7 in plots treated with fungicide until late August as compared with ceasing applications earlier $(P=0.0004)$. Overall, the relative treatment effect was 0.57 (95\% confidence interval 0.52 to 0.61 ) for treatments sprayed with fungicides until late August versus 0.43 (confidence interval 0.39 to 0.48 ) when fungicide applications ceased in late July or early August. Cone color was similar among basal foliage removal treatments $(P=0.162$; Table 2; Fig. 2D).
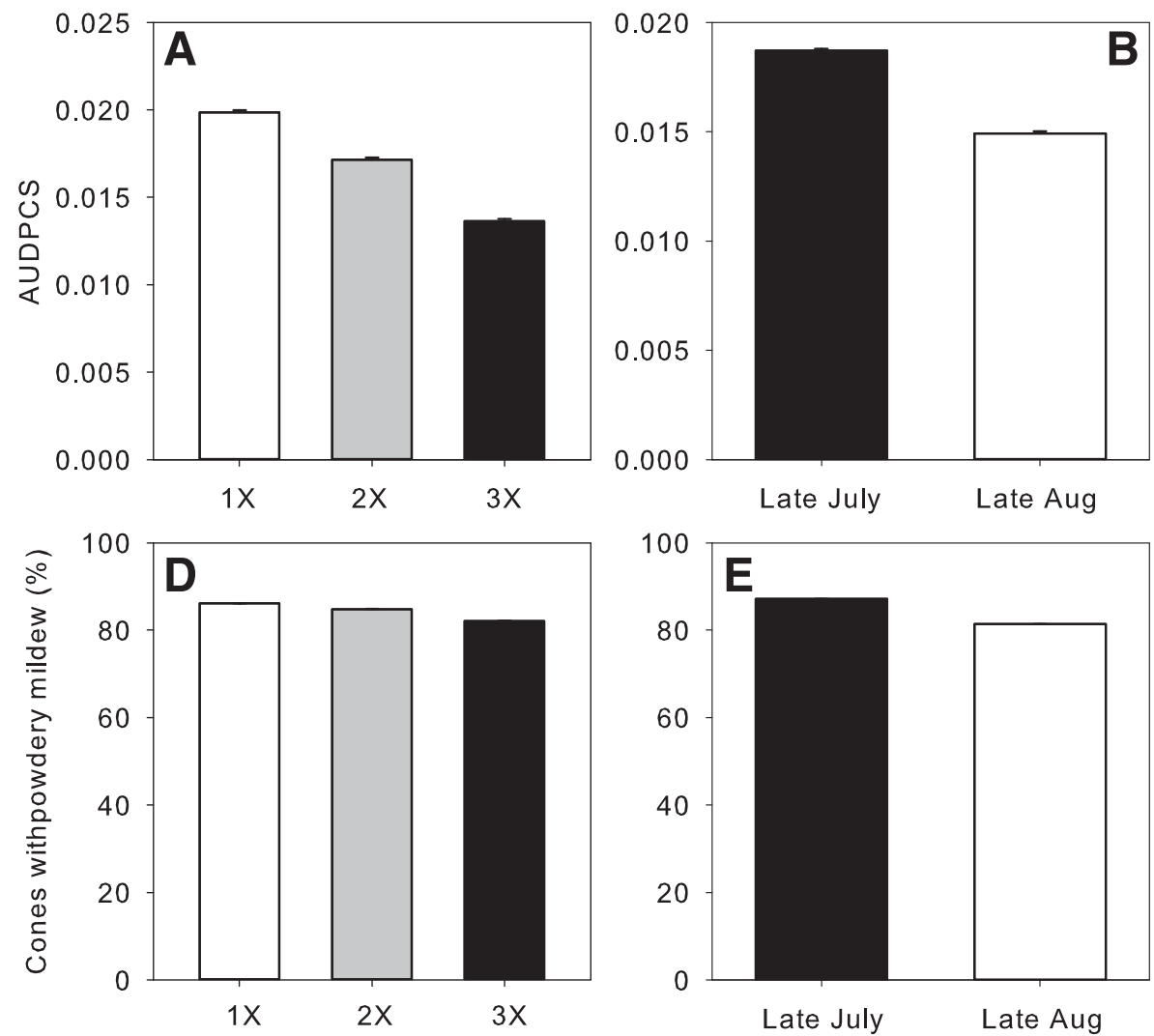

Times basal foliage removed

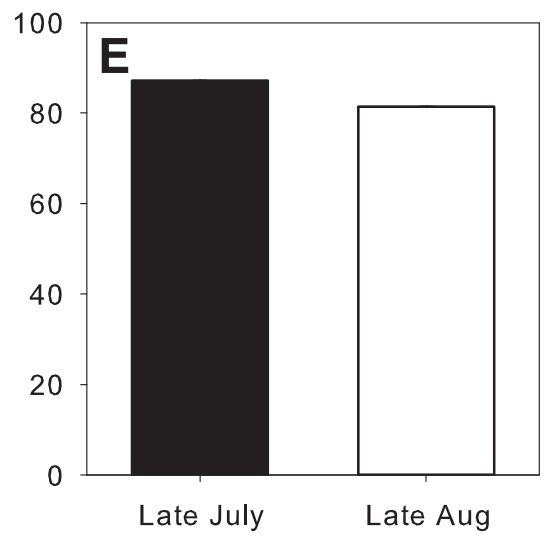

Last fungiicde application
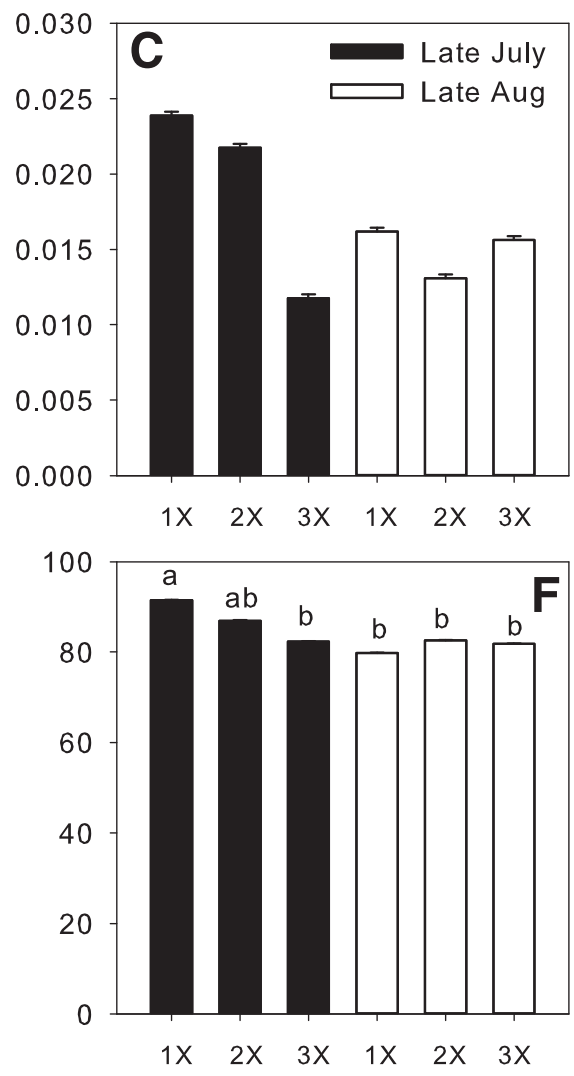

Times basal foliage removed

Fig. 4. Incidence of powdery mildew on hop $\mathbf{A}$ to $\mathbf{C}$, leaves and $\mathbf{D}$ to $\mathbf{F}$, cones in relationship to intensity of basal foliage removal with a desiccant herbicide and duration of fungicide applications in Zeus hop. The same treatments were applied to the same plots in each year from 2012 to 2014, and analyzed as a repeated-measures design in a mixed-effect model. Experiments were conducted in a commercial hop yard near Toppenish, WA. AUDPCS = time-standardized area under the disease progress curve. Letters indicate significant treatment effects based on the mixed-model analysis $(P=0.076)$; absence of letters indicates that a factor was nonsignificant or the interaction term was significant (as in F). Error bars indicate standard errors.

Table 2. Mixed-model repeated-measures analysis of the effect of basal foliage removal (B), duration of fungicide applications (F), and year (Y) on the incidence of hop leaves and cones with powdery mildew, yield, and cone quality factors in experiments with Zeus hopa

\begin{tabular}{|c|c|c|c|c|c|c|c|c|c|c|c|c|c|c|c|c|}
\hline \multirow[b]{2}{*}{ Effect } & \multicolumn{4}{|c|}{ Leaves with powdery mildew ${ }^{b}$} & \multicolumn{4}{|c|}{ Cones with powdery mildew ${ }^{b}$} & \multicolumn{4}{|c|}{ Yield of $\alpha$-acids ${ }^{b}$} & \multicolumn{4}{|c|}{ Cone color ${ }^{\mathrm{c}}$} \\
\hline & N-DF & D-DF & $F$ & $P$ & N-DF & D-DF & $\boldsymbol{F}$ & $P$ & N-DF & D-DF & $F$ & $P$ & N-DF & D-DF & $F$ & $\boldsymbol{P}$ \\
\hline F & 1 & 24.59 & 1.25 & 0.275 & 1 & 24 & 7.92 & 0.001 & 1 & 37.45 & 9.79 & 0.003 & 1 & 46.9 & 9.86 & 0.003 \\
\hline B & 2 & 24.59 & 1.15 & 0.333 & 2 & 24 & 1.33 & 0.283 & 2 & 37.45 & 1 & 0.379 & 1.89 & 46.9 & 1.9 & 0.162 \\
\hline $\mathrm{F} \times \mathrm{B}$ & 2 & 24.59 & 1.44 & 0.256 & 2 & 24 & 2.88 & 0.076 & 2 & 37.45 & 3.07 & 0.058 & 1.89 & 46.9 & 1.51 & 0.232 \\
\hline Y & 2 & 35.23 & 132.28 & $<0.001$ & 2 & 23 & 53.2 & $<0.001$ & 2 & 48.94 & 16.27 & $<0.001$ & 1.96 & 46.9 & 15.75 & $<0.001$ \\
\hline$F \times Y$ & 2 & 35.23 & 1.07 & 0.355 & 2 & 23 & 0.36 & 0.699 & 2 & 48.94 & 0.62 & 0.543 & 1.96 & 46.9 & 4.09 & 0.024 \\
\hline $\mathrm{B} \times \mathrm{Y}$ & 4 & 38.96 & 0.17 & 0.953 & 4 & 26.81 & 0.81 & 0.529 & 4 & 50.74 & 2.39 & 0.063 & 3.56 & 46.9 & 1.08 & 0.374 \\
\hline $\mathrm{F} \times \mathrm{B} \times \mathrm{Y}$ & 4 & 38.96 & 0.7 & 0.594 & 4 & 26.81 & 0.87 & 0.494 & 4 & 50.74 & 0.43 & 0.784 & 3.56 & 46.9 & 0.68 & 0.595 \\
\hline
\end{tabular}

a N-DF and D-DF = numerator and denominator degrees of freedom, respectively.

b Leaves with powdery mildew was expressed as relative area under the disease progress curve. The incidence of cones with powdery mildew was transformed by an angular transformation before analysis. Measurements were repeated over year. Covariance structures for the factor year were selected based on the Akaike Information Criterion. The covariance structures selected for year in the analysis of leaves with powdery mildew, cones with powdery mildew, and yield were heterogeneous compound symmetry, unstructured, and autoregressive, respectively.

c Analysis of cone color was conducted using ranks of cone color rating and an analysis of variance-type statistic, as described by Shah and Madden (2004). 
Yield of $\alpha$-acids varied between years (year effect, $P<0.001$; Table 2) and duration of fungicide applications (fungicide effect, $P=0.003$; Table 2) but these factors did not interact (fungicide-year interaction, $P=0.543$ ). Yield of $\alpha$-acids was reduced $7.3 \%$ in plots where fungicide applications were made until late August compared with plots where fungicide treatments ceased earlier (Fig. 3E). Overall, yield was unaffected by intensity of basal foliage removal (basal foliage removal effect, $P=0.379$; Table 2). There was, however, weak evidence that the duration of fungicide applications interacted with intensity of basal foliage removal in a complex manner in certain treatments (fungicide-basal foliage removal interaction, $P=$ 0.058; Table 2; Fig. 3F).

\section{Discussion}

We have further established that fungicide applications made during the early stages of hop cone development have the strongest effect on suppression of powdery mildew and maximizing cone yield. On the two cultivars evaluated in this work, there was no evidence that fungicide applications made after late July (stages II to III of cone development) significantly influenced the incidence of leaves with powdery mildew. This finding was somewhat expected given that hop leaves develop ontogenic resistance relatively rapidly (Turechek et al. 2001) and that leaf development in hop is determinate and largely ceases after the summer solstice, when plants bloom (Thomas 1967). Consequently, it is common to observe a slow decline in the incidence of leaves with powdery mildew during July and August, independent of fungicide treatment (Gent et al. 2014). On cones, disease control in late July and early August is most critical (Nelson et al. 2015), although we found that fungicide applications made after this period suppressed powdery mildew to varying degrees depending on the year and cultivar. In all instances, though, reductions in disease levels associated with August fungicide applications were modest, commensurate improvements in cone color were observed only in Zeus, and yield of $\alpha$-acids was unimproved in either cultivar.

Disease suppression on cones from fungicide applications made in August was moderated by how thoroughly basal foliage was removed. This was most pronounced in Zeus, with disease suppression from late-season fungicide applications diminished as the intensity of basal foliage removal increased (Fig. 4). A similar interaction of fungicide duration and basal foliage removal was generally apparent in the experiments with Galena but was not solely related to intensity of basal foliage (Fig. 1). In the trials with this cultivar, the data suggest that partial defoliation of basal foliage (from one application of a desiccant herbicide) is no different and potentially worse than no removal of foliage at all. An explanation for this finding might be that partial defoliation of basal growth causes greater disturbance and escape of conidia from the lower canopy compared with no removal of the basal growth; another explanation might be possible stimulation of juvenile leaf growth because of loss of apical dominance of partially defoliated basal shoots.

The interaction of basal foliage removal and duration of fungicide application likely reflects a broader relationship between disease severity and the value of late-season fungicides. As noted previously, the meta-analysis by Nelson et al. (2015) found that the fungicide quinoxyfen is especially efficacious when applied during a 3-week period centered on the transition from bloom to cone development. However, the authors also found that the incidence of leaves with powdery mildew was a significant covariate in some of their analyses, pointing out that efficacy of a carefully timed quinoxyfen application depends on inoculum density. Similarly, Gent et al. (2014) found no overall impact on cone yield when fungicide applications were made after the period of juvenile susceptibility when data were aggregated over all 3 years of the study. However, when analyzed by year, there was evidence of yield improvement from late-season applications in 1 year, when diseases levels on leaves were more severe (i.e., AUDPCS of 0.063 or greater). Thus, the need for late-season fungicide applications appears linked to disease severity. Analogous situations appear with grape powdery mildew (Moyer et al. 2014). However, it appears feasible to eliminate one or more fungicide applications in August when disease pressure is sufficiently low.
Cultural practices such as basal foliage removal play an important role in this regard.

The experiments in Zeus indicate that fungicide applications, as made currently by some producers, may actually reduce yield. Yield of $\alpha$-acids was reduced $7.3 \%$ in plots that received two applications of pyraclostrobin and boscalid, independent of basal foliage removal treatment. Plant-growth-regulating effects from strobilurin fungicides are well known, including a "greening effect" and delayed senescence associated with several physiological processes (Bartlett et al. 2002). The net result of these effects on yield is variable but can be positive in some situations, even in the absence of disease (Paul et al. 2011; Weisz et al. 2011). The reason for yield depression in the present study might be due to physiological processes (phytotoxicity) specific to these fungicides or simply physical injury from the application.

Basal foliage removal has long been recommended as a cultural control method for hop downy mildew and powdery mildew. An impediment to broader adoption of this practice has been concern over negative yield effects in both the current and ensuing season. Carbohydrates stored in the root system are important for future growth and yield in perennial plants, including hop (Rybáček 1991; Williams and Weston 1959). In young plants, Williams (1962) found that removing basal foliage twice in the first year of growth reduced starch reserves in the root system by $41 \%$ in autumn and reduced cone yield $43 \%$ in the following year. In contrast, early literature reported that yield is negligibly affected from basal foliage removal on mature plants where the root system is well developed (Jones and Moss 1959). In the present study, we found no evidence of reduced $\alpha$-acids yield, or components of $\alpha$-acids yields (data not presented), in any individual year or cumulatively from basal foliage removal in two relatively high-yielding cultivars. We caution that this response is likely dependent on cultivar, production region, and other factors that influence the efficiency of carbohydrate partitioning and storage (e.g., drought stress). Future experiments are warranted to determine whether the findings in the present study are valid for earlymaturing cultivars with lower yield potential.

A potential concern with earlier termination of fungicide applications is whether this could increase overwintering inoculum of $P$. macularis for the following season. $P$. macularis is heterothallic and readily forms ascocarps where both mating types of the fungus are present (Wolfenbarger et al. 2015). The ascigerious stage of $P$. macularis has not been reported in the U.S. Pacific Northwest (Ocamb et al. 1999) because of the apparent absence of the MAT1-2 mating type in the region (Wolfenbarger et al. 2015). Consequently, the fungus perennates at a low frequency only by means of bud infection (Gent et al. 2008; Turechek et al. 2001), leading to "flag shoots" in the following year. All plots in this study were inspected each spring for flag shoots and none were found in any year of the experiment.

As a whole, the additive effect of fungicide applications targeted to the periods of greatest cone susceptibility and canopy management to reduce disease favorability may obviate the need for later fungicide applications. In the commercial hop yard study, the value of removing basal foliage three times was equivalent to two applications of fungicides in August. This appears to be a viable strategy in mature hop yards of certain cultivars when disease pressure is not excessively high.

\section{Acknowledgments}

Financial support for this research was provided by Washington State University Agriculture Research Center, Hop Research Council, United States Department of Agriculture-Agricultural Research Service CRIS 5358-21000-040-00, and Washington State Department of Agriculture Specialty Crops Research Block Grant Program. We thank E. Lizotte for providing helpful suggestions that improved this article; and John I. Haas, Inc. for providing resources and facilities that made this work possible.

\section{Literature Cited}

ASBC. 2009. ASBC Methods of Analysis, 14th ed. The American Society of Brewing Chemists, St. Paul, MN.

Austin, C. N., Grove, G. G., Meyers, J. M., and Wilcox, W. F. 2011. Powdery mildew severity as a function of canopy density: Associated impacts on sunlight penetration and spray coverage. Am. J. Enol. Vitic. 62:23-31. 
Austin, C. N., and Wilcox, W. F. 2011. Effects of fruit-zone leaf removal, training systems, and irrigation on the development of grapevine powdery mildew. Am. J. Enol. Vitic. 62:193-198.

Bartlett, D., Clough, J. M., Godwin, J. R., Hall, A. A., Hamer, M., and ParrDobrzanski, B. 2002. The strobilurin fungicides. Pest Manage. Sci. 58:649-662.

Brunner, E., Domhof, S., and Langer, F. 2002. Nonparametric Analysis of Longitudinal Data in Factorial Experiments. John Wiley and Sons, New York.

Chellemi, D. O., and Marois, J. J. 1992. Influence of leaf removal, fungicide applications, and fruit maturity on incidence and severity of grape powdery mildew. Am. J. Enol. Vitic. 43:53-57.

English, J. T., Thomas, C. S., Marois, J. J., and Gubler, W. D. 1989. Microclimates of grapevine canopies associated with leaf removal and control of Botrytis bunch rot. Phytopathology 79:395-401.

Gent, D. H., Grove, G. G., Nelson, M. E., Wolfenbarger, S. N., and Woods, J. L. 2014. Crop damage caused by powdery mildew on hop and its relationship to late season management. Plant Pathol. 63:625-639.

Gent, D. H., Nelson, M. E., George, A. E., Grove, G. G., Mahaffee, W. F., Ocamb, C. M., Barbour, J. D., Peetz, A., and Turechek, W. W. 2008. A decade of hop powdery mildew in the Pacific Northwest. Online publication. Plant Health Prog. doi:10.1094/PHP-2008-0314-01-RV.

Gent, D. H., Nelson, M. E., Grove, G. G., Mahaffee, W. F., Turechek, W. W., and Woods, J. L. 2012. Association of spring pruning practices with severity of powdery mildew and downy mildew on hop. Plant Dis. 96:1343-1351.

Hed, B., Ngugi, H. K., and Travis, J. W. 2015. Short- and long-term effects of leaf removal and gibberellin on Chardonnay grapes in the Lake Erie Region of Pennsylvania. Am. J. Enol. Vitic. 66:22-29.

Jarvis, W. R., Gubler, W. D., and Grove, G. G. 2002. Epidemiology of powdery mildews in agricultural pathosystems. Pages 169 to 199 in: The Powdery Mildews, A Comprehensive Treatise. R. Belanger, W. R. Bushnell, A. J. Did, and T. L. W. Carver, eds. American Phytopathological Society, St. Paul, MN.

Jones, E. L., and Moss, N. 1959. Report on the Experimental Work on Hops. Rosemaund Experimental Husbandry Farm, Preston Wynne, Herefordshire, UK.

Kavalier, A. R., Litt, A., Ma, C., Pitra, N. J., Coles, M. C., Kennelly, E. J., and Matthews, P. D. 2011. Phytochemical and morphological characterization of hop (Humulus lupulus L.) cones over five developmental stages using high performance liquid chromatography coupled to time-of-flight mass spectrometry, ultrahigh performance liquid chromatography photodiode array detection, and light microscopy techniques. J. Agric. Food Chem. 59:4783-4793.

Madden, L. V., Hughes, G., and Van den Bosch, F. 2007. The Study of Plant Disease Epidemics. American Phytopathological Society, St Paul, MN

Mahaffee, W. F., Engelhard, B., Gent, D. H., and Grove, G. G. 2009. Powdery mildew. Pages 25 to 31 in: Compendium of Hop Diseases and Pests. W. F. Mahaffee, S. J. Pethybridge, and D. H. Gent, eds. American Phytopathological Society, St. Paul, MN.

Merry, A. M., Evans, K. J., Corkrey, R., and Wilson, S. J. 2013. Coincidence of maximum severity of powdery mildew on grape leaves and the carbohydrate sink-to-source transition. Plant Pathol. 62:842-850.

Moyer, M. M., Gadoury, D. M., Wilcox, W. F., and Seem, R. C. 2014. Release of Erysiphe necator ascospores and impact of early season disease pressure on Vitis vinifera fruit infection. Am. J. Enol. Vitic. 65:315-324.
Nelson, M. E., Gent, D. H., and Grove, G. G. 2015. Meta-analysis reveals a critical period for management of powdery mildew on hop cones. Plant Dis. 99: 632-640.

Neve, R. A. 1991. Hops. Chapman and Hall, London.

Ocamb, C., Klein, R., Barbour, J., Griesbach, J., and Mahaffee, W. 1999. First report of hop powdery mildew in the Pacific Northwest. Plant Dis. 83: 1072.

Paul, P. A., Madden, L. V., Bradley, C. A., Robertson, A. E., Munkvold, G. P. Shaner, G., Wise, K. A., Malvick, D. K., Allen, T. W., Grybauskas, A., Vincelli, P., and Esker, P. 2011. Meta-analysis of yield response of hybrid field corn to foliar fungicides in the U.S. Corn Belt. Phytopathology 101: $1122-1132$.

Romanko, R. R. 1964. Control of hop downy mildew by chemical desiccants Phytopathology 54:1439-1442.

Royle, D. J. 1978. Powdery mildew of the hop. Pages 381-409 in: The Powdery Mildews. D. M. Spencer, ed. Academic Press, New York.

Royle, D. J., and Kremheller, H. T. H. 1981. Downy mildew of the hop. Pages 395-419 in: The Downy Mildews. D. M. Spencer, ed. Academic Press, New York.

RybáčekV., ed. 1991. Hop Production. Elsevier Science Publishing Company, New York.

Shah, D. A., and Madden, L. V. 2004. Nonparametric analysis of ordinal data in designed factorial experiments. Phytopathology 94:33-43.

Sherman, J., and Gent, D. H. 2014. Concepts of sustainability, motivations for pest management approaches, and implications for communicating change. Plant Dis. 98:1024-1035.

Thomas, C. S., Marois, J. J., and English, J. T. 1988. The effects of wind speed, temperature, and relative humidity on development of aerial mycelium and conidia of Botrytis cinerea on grape. Phytopathology 78:260-265.

Thomas, G. G. 1967. Hop studies by late I. H. Williams. Rep. Dep. Hop Res. Wye Coll. 1966:63-67.

Turechek, W. W., Mahaffee, W. F., and Ocamb, C. M. 2001. Development of management strategies for hop powdery mildew in the Pacific Northwest. Online publication. Plant Health Prog. doi:10.1094/PHP-2001-0313-01-RS.

Twomey, M. C., Wolfenbarger, S. N., Woods, J. L., and Gent, D. H. 2015 Development of partial ontogenic resistance to powdery mildew in hop cones. PLoS One 10:e0120987.

Weisz, R., Cowger, C., Ambrose, G., and Gardner, A. 2011. Multiple mid-Atlantic field experiments show no economic benefit to fungicide application when fungal disease is absent in winter wheat. Phytopathology 101:323-333.

Williams, I. H. 1962. The effect of stripping and cutting upon the carbohydrate status and yield of young hops. Rep. Dep. Hop Res. Wye Coll. 1961: 59-68.

Williams, I. H., and Weston, E. W. 1959. Changes in the carbohydrate balance of the hop (Humulus lupulus L.). Rep. Dep. Hop Res. Wye Coll. 1958:55-61.

Wolfenbarger, S. N., Twomey, M. C., Gadoury, D. M., Knaus, B. J., Grünwald, N. J., and Gent, D. H. 2015. Identification and distribution of mating-type idiomorphs in populations of Podosphaera macularis and development of chasmothecia of the fungus. Plant Pathol. 64:1094-1102. 